\title{
High prevalence of Type 2 (non-insulin-dependent) diabetes among the offspring of conjugal Type 2 diabetic parents in India
}

\author{
M. Viswanathan, V. Mohan, C. Snehalatha and A. Ramachandran \\ V.R. Ramanath Laboratory for Advanced Research in Diabetes, Diabetes Research Centre, Royapuram, Madras, India
}

\begin{abstract}
Summary. The prevalence of Type 2 (non-insulin-dependent) diabetes among offspring of conjugal Type 2 diabetic parents in India was determined by performing oral glucose tolerance tests. Diabetes was present in 50\% of offspring, and $12 \%$ had impaired glucose tolerance according to the National Diabetes Data Group criteria. Thus, $62 \%$ of all offspring had abnormal glucose tolerance tests. This is the highest prevalence rate
\end{abstract}

for diabetes among offspring of conjugal diabetic parents and might represent an ethnic variation of the genetic factors operating in Indian patients with Type 2 (non-insulin-dependent) diabetes.

Key words: Conjugal diabetes, India, Type 2 diabetes, genetics, ethnic variation.
The prevalence of Type 2 (non-insulin-dependent) diabetes in offspring of conjugal Type 2 diabetic parents has been reported from several centres [1-4]. Most of the studies have been carried out in European races. There is general consensus that the prevalence of 'overt' diabetes in this group of individuals is low and ranges between $3 \%$ and $12 \%$ [5]. When glucose tolerance tests are done, asymptomatic diabetes is seen in $10-35 \%$ of offspring of conjugal diabetic parents [6].

We [7] and others [8] have reported that Type 2 (noninsulin-dependent) diabetes in the Indian population differs in several respects from that seen in western countries. These differences include younger age at diagnosis, predominance of males and lower prevalence of obesity [8]. We have recently shown that there are differences in the genetics of Type 1 diabetes in India [9]; however, there is very little data on the genetics of Type 2 diabetes in India. For these reasons, we studied the prevalence of Type 2 diabetes among offspring of conjugal diabetic parents of Indian origin.

\section{Subjects and methods}

\section{Subjects}

A series of 2600 conjugal diabetic parents was registered at the Diabetes Research Centre, Madras, S. India, as part of a project on primary prevention of diabetes [10]. Family members were motivated by a special educational programme on primary prevention of diabetes, and were invited to participate in this programme. Over 400 families vol- unteered to undergo tests at the centre; however, in many of these families all the offspring could not be tested. In some cases where the offspring could not come to our centre for the tests, oral glucose tolerance tests were arranged by their own physicians. The guidelines laid down by the National Diabetes Data Group [11] were used for performing the glucose tolerance tests. In 164 families, all the offspring were tested. In 55 of these families, the proband was a parent; in the remaining 109 , an offspring was the proband. In 75 of the latter group, the proband had diabetes.

A questionnaire was used to elicit all relevant details of diabetes including the age at diagnosis, type of treatment and clinical status of the parents and siblings. A full pedigree was drawn up for every family. The accuracy of this was confirmed by questioning at least one more member of the family wherever possible. Diagnosis of Type 2 diabetes was based on the following criteria: absence of ketosis at any time and adequate control of diabetes for a minimum period of 2 years without insulin.

Of the 164 families studied, $81 \%$ were Hindus, $10 \%$ Muslims and $9 \%$ Christians. The families belonged to the four southern states of India, namely Tamil Nadu, Andhra Pradesh, Kerala and Karnataka. The 164 conjugal diabetic parents produced a total of 603 offspring. Twenty-one of the offspring died either in childhood or during adolescence due to unrelated conditions. Two died of diabetic renal disease at age 26 and 48 years, respectively. The remaining 580 offspring underwent blood tests for the diagnosis of diabetes at least once. 410 were tested at our centre. Oral glucose tolerance tests were performed using $75 \mathrm{~g}$ glucose. Wherever the fasting plasma glucose values were diagnostic of diabetes, the glucose tolerance tests were abandoned. Plasma glucose was estimated by the O-toluidine method [12]. Every effort was made to trace the records of the investigations performed on the 170 individuals tested elsewhere. In indiyiduals whose results were not available, diagnosis of diabetes was accepted if they were being treated either with insulin or oral hypoglycaemic agents.

A group of 144 age- and sex-matched control subjects without a family history of diabetes were also tested. Three individuals of this group were found to have abnormal glucose tolerance tests. 
Table 1. Details of offspring of conjugal Type 2 diabetic parents

\begin{tabular}{lllll}
\hline & $\begin{array}{l}\text { Total } \\
\text { number }\end{array}$ & $\begin{array}{l}\text { Number } \\
\text { with } \\
\text { Type 2 } \\
\text { diabetes }\end{array}$ & $\begin{array}{l}\text { Number } \\
\text { with } \\
\text { impaired } \\
\text { glucose } \\
\text { tolerance }\end{array}$ & $\begin{array}{l}\text { Number } \\
\text { with normal } \\
\text { results }\end{array}$ \\
\hline $\begin{array}{l}\text { Offspring tested } \\
\text { at the Diabetes } \\
\text { Research Centre }\end{array}$ & 410 & 177 & 60 & 173 \\
$\begin{array}{l}\text { Offspring tested } \\
\text { elsewhere }\end{array}$ & 170 & 110 & 10 & 50 \\
\hline Total & 580 & 287 & 70 & 223 \\
\hline
\end{tabular}

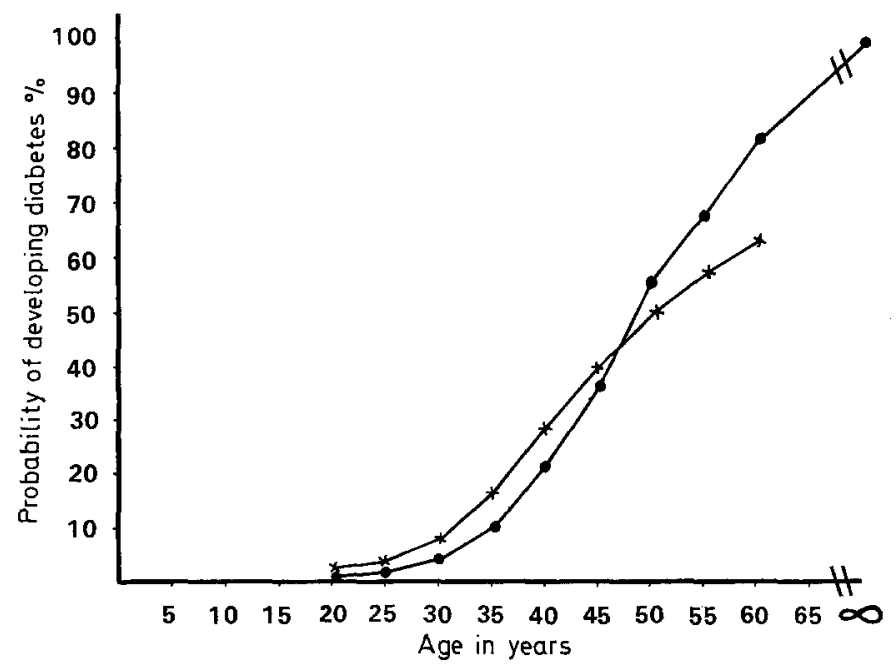

Fig.1. The comparison of the age at onset of Type 2 diabetes in offspring with that in parents using the Kolmogrov-Smirnoff test. $x-x$ offspring, - parents

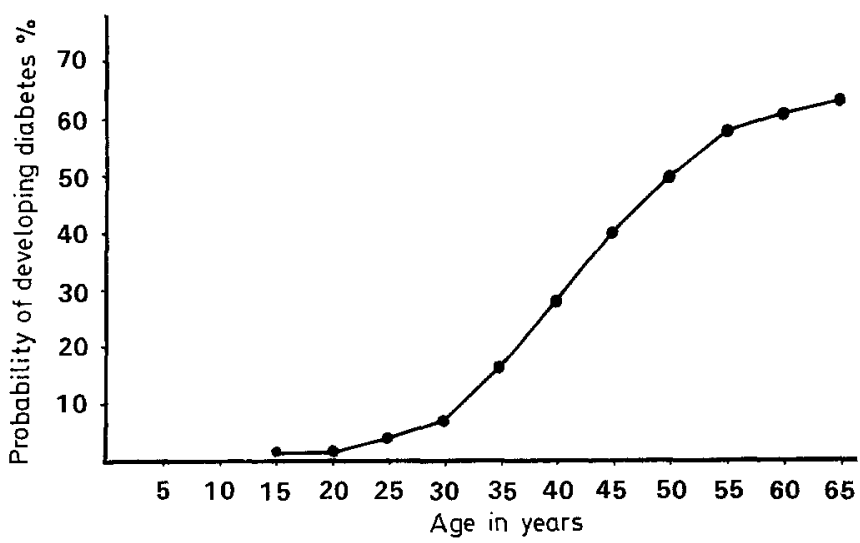

Fig. 2. The cumulative risk of developing Type 2 diabetes in offspring using the Kaplan-Meir product-limit estimate

Body mass index was calculated using the formula $\mathrm{Wt}(\mathrm{Kg}) / \mathrm{Ht}$ $\left(\mathrm{m}^{2}\right)$. Obesity was defined as BMI $>25$ for women and $>27$ for men. Men with $\mathrm{BMI}<19$ and women with $\mathrm{BMI}<18$ were classified as lean.

\section{Statistical analysis}

The Kolmogrov-Smirnov two-sample test was used to compare the empirical distribution functions of the parents and the offspring with respect to probability of developing diabetes with increasing age. The probable risk of diabetes in the offspring was computed using the Kaplan-Meir product limit estimate.

\section{Results}

Type 2 diabetes in the parents.

All parents had Type 2 diabetes. The mean age at diagnosis in the fathers was 45 years and in mothers 42 years. The mean duration of diabetes was $11 \pm$ 2 years, and $25 \%$ of the parents were obese.

\section{Type 2 diabetes in the offspring.}

The 580 offspring consisted of 298 men and 282 women. $287(50 \%)$ were classified as diabetic and $70(12 \%)$ had impaired glucose tolerance (Table 1). Thus, a total of $357(62 \%)$ showed abnormal carbohydrate tolerance. Henceforth these 357 offspring will be referred to as 'diabetic' for the reasons mentioned below.

The 357 diabetic offspring consisted of 187 males and 170 females. Fifty-nine percent of the offspring were of ideal body weight, $38 \%$ obese and $3 \%$ lean. The comparison of the age at diagnosis of diabetes in the offspring with that in the parents was done using the Kolmogrov-Smirnov test and is shown in Figure 1. It was seen that the distribution of the survival probability was different in the two groups. The probability of developing diabetes was higher in the offspring up to the age of 45 years. Diabetes was not diagnosed below the age of 20 years in any of the parents. It occurred in three of the offspring in this age group. C-peptide assay done in these three patients showed that all had Type 2 diabetes [fasting C-peptide $>0.3 \mathrm{pmol} / \mathrm{ml}$; post-prandial Cpeptide $>0.6 \mathrm{pmol} / \mathrm{ml}$, the values noted for Type 2 diabetic patients at our centre [7].]

\section{Type of treatment}

In parents. Two hundred and ninety parents (91\%) were treated with oral hypoglycaemic agents, while $38(9 \%)$ had received insulin after a mean duration of diabetes of 13 years.

In offspring. Except for 10 of the offspring who required insulin after a mean duration of 15 years, all offspring were treated either with diet alone (those with impaired glucose tolerance) or with oral agents.

\section{Probable risk of developing Type 2 diabetes}

Using the Kaplan-Meir product limit test, the cumulative risk of developing diabetes if all offspring were followed to the age of 60 years was computed (Fig. 2). It was seen that by the age of 60 years, $63 \%$ of the offspring may be expected to develop diabetes. 
Table 2. Family size and the number of children with Type 2 diabetes

\begin{tabular}{lrrrrrrrrrrr}
\hline $\begin{array}{l}\text { Family size } \\
\text { (no. of children) }\end{array}$ & \multicolumn{1}{c}{ Number of children with Type 2 diabetes } \\
\cline { 2 - 10 } & 0 & 1 & 2 & 3 & 4 & 5 & 6 & 7 & 8 & 9 & 10 \\
\hline 1 & 9 & 32 & & & & & & & & \\
2 & 6 & 2 & 14 & & & & & & & \\
3 & 4 & 4 & 3 & 12 & & & & & & & \\
4 & 4 & 6 & 6 & 3 & 12 & & & & & \\
5 & 1 & 4 & 2 & 2 & 3 & 4 & & & & \\
6 & 1 & 4 & 1 & 2 & 2 & 3 & 2 & & & & \\
7 & - & - & 1 & - & 2 & 1 & 1 & - & & & \\
8 & 1 & - & 1 & - & - & 1 & 1 & 1 & 2 & & \\
9 & - & - & - & - & 2 & 1 & - & - & - & - & - \\
10 & - & - & - & - & - & - & - & - & - & - & 1 \\
\hline Total & 26 & 52 & 28 & 19 & 21 & 10 & 4 & 1 & 2 & - & 1 \\
\hline
\end{tabular}

\section{Family size and number of Type 2 diabetic offspring}

The size of the families and the number of diabetic children in the different family groups is shown in Table 2. In 79 families (48\%), all offspring were diabetic. In 32 of these families, there was only one offspring in each family. In 26 families (16\%), none of the offspring were diabetic. However, 42 out of the 68 offspring in these 26 families were below the age of 40 years.

\section{Discussion}

This study brings out the high prevalence of Type 2 diabetes among offspring of conjugal Type 2 diabetic Indian families. Overt diabetes was present in $50 \%$ of the offspring. If impaired glucose tolerance and diabetes were combined, $62 \%$ had abnormal glucose tolerance. This is the highest prevalence rate for Type 2 diabetes among offspring of conjugal Type 2 diabetic parents reported so far.

In this study we chose to combine the numbers of the diabetic patients and those with impaired glucose tolerance for a number of reasons. Firstly, most earlier studies used the Fajans and Conn criteria in which a 2-h value over $6.6 \mathrm{mmol} / \mathrm{l}$ was sufficent to diagnose diabetes $[4,5,13]$. In the National Diabetes Data Group criteria, even for the diagnosis of impaired glucose tolerance, the 2-h value must be more than $7.8 \mathrm{mmol} / \mathrm{l}$. Moreover, the peak value should be $>11 \mathrm{mmol} / 1$ as opposed to $9 \mathrm{mmol} / \mathrm{l}$ in the Fajans and Conn criteria. Therefore, in order to compare prevalence rates in our study with those reported earlier, we felt it was useful to include diabetes and impaired glucose tolerance under one group. Moreover, we found that $34 \%$ of our patients with impaired glucose tolerance developed diabetes over a period of 5 years (unpublished observation). While the prevalence rate in this study is $62 \%$, the prevalence in the three largest series in Europeans were 23\% [4], 42\% [5] and 45\% [13] after a single oral glucose tolerance test. No doubt these latter figures might be lower if the National Diabetes Data Group criteria were used.
The only large study in European races which reported high prevalence rates for diabetes among offspring of conjugal diabetics is that of Pavel and Pipeata from Rumania [14]. Twenty-eight per cent of their offspring had diabetes. However, in that study the exact criteria for diabetes was not given; hence, some latent diabetic subjects may have been included.

Kahn et al. [4], using repeated glucose tolerance tests, found that $41-62 \%$ of offspring of conjugal diabetic parents had 'chemical' diabetes, but other groups $[5,14]$ did not find similar results. Using the triamcinolone primed glucose tolerance test, Navarette and Tores [15] found that $67 \%$ of offspring of conjugal diabetic parents had abnormal glucose tolerance tests. However, the reproducibility of the cortisone primed glucose tolerance test has been questioned [6].

It might be argued that there is a bias towards a higher percentage of diabetic patients in this study because families ascertained via diabetic offspring have been included. This, however, cannot account for the differences in the prevalence of diabetes observed since most studies have included similarly ascertained families. In the report of Tattersall and Fajans [5], while 15 families were ascertained via parents, 11 were through a diabetic offspring. If ascertainment was done only via parents, most of our offspring would be very young, with many below the age of 20 years. Since only $1 \%$ of the diabetic offspring in the study were below this age, the data collected from such a series would not be helpful. Also, it has been pointed out that ascertainment via parents alone is necessary only when the series is small [5].

Few studies have reported on families where all the members have been tested for diabetes. This could be one of the reasons for the high prevalence of diabetes in our study. Previous studies on this subject have been done prior to 1979 before the new classification into Type 1 and Type 2 diabetes was introduced [11]. Since the age at onset rather than insulin dependency had formerly been used, it is possible that some of the subjects studied by earlier authors could have been the offspring of a Type 1 and a Type 2 diabetic mating. This could considerably influence the prevalence rate of diabetes, since it is generally believed that genetic influences are stronger in Type 2 than in Type 1 diabetes.

It is possible that the high prevalence of Type 2 diabetes among the offspring of conjugal Type 2 diabetic parents in India might be due to ethnic differences in the genetic factors operating in diabetes. A recent study of pancreatic B cell function, using C-peptide as a marker in 'normal' offspring of conjugal diabetic parents of European origin, failed to show any abnormalities in $B$ cell reserve [16]. Studying an identical group of offspring of conjugal diabetic parents of Indian origin, we found evidence of decreased pancreatic B cell function in a significant number of our subjects [17]. This raises two interesting points: firstly, it strengthens the possibility of ethnic differences in the susceptibility of offspring 
of conjugal diabetic parents for developing diabetes; second, it could also mean that many of our offspring of conjugal diabetic parents who have normal glucose tolerance might develop diabetes later.

No definite inference regarding the mode of inheritance of Type 2 diabetes could be drawn from this study. Using a product-limit estimate test, we found that $63 \%$ of all offspring of conjugal Type 2 diabetic parents could be expected to show diabetes by the age of 60 years. Since age correction involves a number of assumptions, the estimation of the ultimate prevalence rate by this method remains controversial. The fact that in 26 families none of the offspring had diabetes, though 25 offspring of these families were above the age of 40 years, suggests that genetic heterogeneity exists among offspring of conjugal diabetic parents even in India. We have recently shown that autosomal dominant forms of diabetes are also commonly seen in India [18]. If we look at all Type 2 diabetic patients seen at our centre, only about $10 \%$ are the offspring of conjugal diabetic parents. This implies that, while families with a strong genetic input breed diabetes, environmental factors appear to play an important role in others. A large study using complex segregation analysis is now in progress in order to delineate the genetic modes of inheritance operating in diabetic patients in India.

\section{References}

1. Cooke AM, Fitzgerald MG, Malins J, Pyke DA (1966) Diabetes in children of diabetic couples. Br Med J 2: 674-679

2. Taton J, Pometta D, Camerini Davlos RA, Marble A (1964) Genetic determinism to diabetes and tolerance to glucose. Lancet 2: 1360-1362

3. Simpson NE (1964) Multifactorial inheritance. A possible hypothesis for diabetes. Diabetes 13:462-468

4. Kahn CB, Soeldner JS, Gleason RE, Rojas L, Camerini Davlos RA, Marble A (1969) Clinical and chemical diabetes in offspring of diabetic couples. N Eng J Med 281: 343-347

5. Tattersall RB, Fajans SS (1975) Prevalence of diabetes and glucose intolerance in 199 offspring of thirty-seven conjugal diabetic parents. Diabetes $21: 452-462$
6. Tattersall RB (1976) Diabetes in offspring of conjugal diabetic parents. In: Creuzfeldt W, Kobberling J, Neel JV (eds) Genetics of diabetes mellitus. Springer, Heidelberg Berlin, pp 188-193

7. Mohan V, Ramachandran A, Viswanathan M (1984) Tropical diabetes. In: Krall LP, Alberti KGMM (eds) Diabetes annual. Excerpta Medica, Amsterdam, pp 82-92

8. West KM (1980) Diabetes in the tropics: some lessons for western diabetology. In: Podolsky S, Viswanathan M (eds) Secondary diabetes. Raven, New York, pp 249-259

9. Kirk RL, Ranford PR, Viswanathan M, Mohan V, Ramachandran A, Snehalatha C, Chetty SMM, John L (1983) Another association between properdin system $(\mathrm{Bf})$ and insulin dependent diabetes in S. India. Tissue Antigens 22: 120-121

10. Mohan V, Ramachandran A, Viswanathan M (1983) Primary prevention of diabetes. A project of the Diabetes Research Centre, Madras. Bull Del Health Care Develop Countries 4: 9-13

11. National Diabetes Data Group (1979) Classification of diabetes and other categories of glucose intolerance. Diabetes 28: 1039-1057

12. Hyvarinen A, Nikkila EA (1962) A specific determination of blood glucose with ortho-toluidine. Clin Chim Acta 7:140-145

13. Radder JK, Terpstra J (1975) The incidence of diabetes mellitus in the offspring of diabetic couples. Diabetologia 11: 135-138

14. Pavel I, Pipetea R (1968) On the mode of transmission of hereditary diabetes. Diabetologia 4: 358-364

15. Navarette VN, Torres IH (1967) Triamcinolone provocative test in offspring of two diabetic parents. Diabetes 16: 57-59

16. Bonora E, Zavaroni I, Bruschi F, Alpi O, Pezzarossa A, Dall'Aglio E, Coscelli C, Butturani U (1984) Evidence for unimpaired pancreatic secretion and hepatic removal of insulin in healthy offspring of Type 2 diabetic couples. Horm Res 20: 138-142

17. Snehalatha C, Mohan V, Ramachandran A, Jayashree R, Viswanathan M (1984) Pancreatic beta cell function in offspring of conjugal diabetic parents. Assessment by IRI and C-peptide ratio. Horm Metab Res 16 (Suppl): 142-144

18. Mohan V, Ramachandran A, Snehalatha C, Mohan R, Viswanathan M (1985) High prevalence of maturity onset diabetes of the young in S. India. Diabetes Care 8: 371-374

Received: 4 December 1984

and in revised form: 11 June 1985

Dr. M. Viswanathan

Diabetes Research Centre

5, Main Road

Royapuram

Madras 600013

India 